\title{
Desequilibrios regionales y políticas de equilibrio en las áreas de montaña
}

\author{
JAVIER COLOMO UGARTE*
}

RESUMEN SUMMARY

Las políticas de ayudas sectoriales no han resuelto la degradación de las áreas

de montaña. Para la conservación de estos espacios habitados, debe tenerse en cuenta el conjunto de sus problemas socioeconómicos; por ello, la adscripción de las ayudas debiera realizarse de manera integral. El ámbito de comarcas es el más lógico para la aplicación y gestión de políticas integrales, que reúne la mayoría de los factores sobre los que debe incidir el desarrollo local.
Sector aid policy have not resolved the decline in mountainous areas. The conservation of this inhabited zones needs to take into account all its socioeconomic problems; that is why allocation of the help should be curried through in an integral manner. Whithin the limits of the region is the suitable place for realization and management of that integral policy, since it has the majority of the factors about which the regional development should fall upon.

\section{INTRODUCCIÓN}

A los desequilibrios interterritoriales, producidos en el proceso de transformación de una sociedad rural a otra urbana, han venido a añadirse los generados por la ampliación del espacio común de mercado en la Unuón Europea, entrando en crisis los sectores económicamente menos competitivos. Cuando ha coincidido que éstos representaban el modo de vida principal de algunas regiones o comarcas, la crisis del sector se ha convertido

* Doctor en Geografía. 
en la propia de la comarca o región. Tal ha sido el caso de algunas comarcas mineras, lecheras, etc. Las áreas de montaña, por sus características productivas, han padecido la incidencia de ambas dinámicas.

Con el fin de mitigar los efectos negativos de estas dinámicas económicas, durante las últimas décadas en el ámbito de la UE, y principalmente a partir de los años ochenta en España, se han estado aplicando políticas tendentes a aminorar los desequilibrios con estos espacios. En lo que respecta a las áreas de montaña, contempladas dentro de las áreas rurales deprimidas, el objetivo de estas políticas ha sido preservar la capacidad productiva de las mismas, de forma que no se perdieran actividades económicas como la producción de carne o leche, sometidas a la competencia desde espacios más cualificados productivamente, y ello, no tanto por la necesidad que de esos productos precise el mercado comunitario, sino por ser la única forma de asegurar la continuidad de los asentamientos humanos en estos espacios, de gran valor histórico, cultural, ecológico y humano.

\section{REVALORIZACIÓN RECIENTE Y DESARROLLO DE LA MONTAÑA}

Desde ese punto de vista, hay que considerar que éstas politicas en las áreas de montaña deben de tener un enfoque global, pues solamente pueden ser válidas si garantizan la continuidad de un umbral demográfico suficiente para mantener una población equilibrada. Este umbral es posible sólo cuando existen los recursos necesarios para que la población residente pueda asegurar su medio de vida. Ello, dentro de las necesidades del hombre moderno, no solamente viene determinado por el desenvolvimiento normal de las actividades económicas, sino que debe venir acompañado de unas infraestructuras necesarias capaces de proporcionar los servicios que el modelo medio de vida urbano circundante ofrece.

En los últimos tiempos, no solamente existe una emergente valoración del espacio de montaña por parte de sus habitantes, sino que una nueva utilidad humana se le ha conferido por miles de personas foráneas: la del deporte y el ocio. Esta revalorización en la utilización humana del territorio une los espacios urbano y rural en un doble sentido; mientras el habitante local necesita de redes de carreteras para sus desplazamientos a la ciudad en busca de servicios, el foráneo las necesita para acceso a los lugares de recreo. El espacio de montaña paradójicamente, a pesar de tener en la actualidad menos habitantes estables que en tiempos anteriores, se encuentra más hollado por el ser humano que en la época del modelo tradicional de vida de montaña; $y$, además, con más riesgo de deterioro medioambiental. 
Esta corriente humana de la ciudad a la montaña puede y debe ser utilizada, en estos espacios, para articular un modelo de desarrollo económico que se base no solamente en el sector primario y en las escasas industrias existentes sino de manera importante en el sector servicios y, dentro del mismo, principalmente en la actividad de hostelería. El turismo puede, mejor que otras actividades económicas, revalorizar el entorno natural de una zona, a través de medidas de conservación y mejora de la calidad ambiental, ya que sólo un entorno bien conservado tiene un valor real para la actividad turística e incluso la economía, la sociedad y la política de una región (Fayos, D.; Sancho, A., 1996).

El concepto de desarrollo ha cambiado bastante en los últimos años, de tal manera que con el mismo podemos estar refiriéndonos a distintas actuaciones socioeconómicas. El desarrollo asociado al crecimiento económico duro, sin tener en cuenta otra serie de variables, antepone la magnitud macroeconómica a otros aspectos de tipo social o ecológico; en este paradigma económico, solamente es socialmente aceptable lo que económicamente es rentable. Este modelo utilizado principalmente en zonas muy industrializadas o urbanas, no se adapta a otras con umbrales ecológicos o demográficos más frágiles como las áreas de montaña que no admiten impactos importantes de antropización que repercutirían de forma negativa e irreversible en especies de plantas y animales y recursos naturales como el agua.

En el otro extremo de preservación de estos espacios estaría el modelo de desarrollo asistencial. Este modelo también debe ser cuestionado, pues la consideración de que un espacio debe ser parcialmente asistido no debe suponer una tutela a la mera residencia, sino un estímulo al aprovechamiento integral de los recursos y las iniciativas que se promuevan. En el ámbito de la UE, el concepto de desarrollo para las áreas rurales deprimidas se orienta a preservar lo social por encima de la pura rentabilidad, compensando sus déficits con ayudas económicas procedentes de espacios más aptos para el desarrollo económico. No obstante, en las áreas calificadas como zonas rurales de montaña, cabe decir que apenas se han beneficiado del crecimiento económico habido en estas últimas décadas, pues éste se ha producido de espaldas y relativamente alejado de ellas, concentrando actividades productivas y población en los núcleos urbano-industriales. Dicho crecimiento económico ha tenido lugar en el marco de un modelo de desarrollo que conlleva importantes desequilibrios, tratándose por ello de un modelo cuando menos cuestionable si se consideran las demandas de la sociedad actual (Murua, J.; Malagón, E.; Nebreda, A., 1996). 


\section{POLITICAS INTEGRALES Y DESARROLLO SOSTENIBLE: UNA NECESIDAD PARA EL FUTURO DE LAS ÁREAS DE MONTAÑA}

En estas comarcas, en el desarrollo de sus actividades económicas, se debe de atender a dos aspectos fundamentales: los sociales y el umbral ecológico; por ello, no todas las actividades propuestas pueden ser aceptadas como válidas para el desarrollo de la comarca, sino solamente aquellas que se encuentren dentro de unos límites tolerables, descartando el resto; me estoy refiriendo en concreto a la instalación de grandes complejos turísticos o a la construcción de obras que, sin ser de interés general para el conjunto de la sociedad, afectan negativamente al entorno naturalístico como, pistas forestales, industrias contaminantes, etc.

Este modelo de desarrollo que permite garantizar el modo de vida de las generaciones presentes y de las futuras, al que ha venido en denominarse desarrollo sostenido o sostenible, debe ser la base para las actuaciones en las áreas de montaña. Qué duda cabe que su éxito depende de todas las personas y organismos sensibilizados por esta problemática, pero quienes deben de ser los protagonistas son los propios habitantes de la zona y las administraciones públicas locales. Mientras que en lo relativo a infraestructuras y servicios sociales es necesaria la ayuda de las administraciones públicas, en lo referente a las actividades económicas, la capacidad para generar proyectos concretos de desarrollo depende principalmente de las iniciativas locales, bien individuales o colectivas, siendo las ayudas económicas exteriores un factor importante pero no decisivo; por ello, la tarea de formación de las generaciones jóvenes en actividades rentables para el aprovechamiento de los recursos de la montaña es una inversión de futuro.

El concepto de política integral referido al ámbito de las comarcas de montaña ha venido definiéndose en oposición a la insuficiencia demostrada de las políticas de ayuda sectoriales, al constatarse que las mismas no resuelven su degradación socioeconómica y al entender que, para la conservación de estos espacios habitados, debe tenerse en cuenta el conjunto de sus problemas, económicos, de servicios asistenciales, infraestructuras, comunicaciones, etc. Esta necesidad es propia de comarcas de montaña con una fuerte tradición en el uso humano del territorio donde la conservación de las riquezas naturalísticas están intimamente unidas a la continuidad de los asentamientos humanos. "Lo que nosotros proponemos ahora es una política integral. Bruselas debería entender de una vez que el desarrollo de las regiones de montaña no es cuestión de política agrícola. La política agrícola es uno de los factores dentro del sistema, pero está en 
relación con otras actividades: turismo, transporte, forestal, industria; pero, insisto, habría que llegar a una política integral» (Wyder, J., 1989).

El concepto de ayuda sectorial parte del supuesto de creer que, una vez determinados los déficits de una comarca, éstos se pueden solucionar con ayudas sectoriales. Esta visión no deja de ser en numerosas ocasiones muy parcial, pues, aunque hay que tener en cuenta que toda ayuda contribuye a paliar el deterioro del espacio de montaña, el objetivo por el cual ésta se realiza no es asegurar en sí misma la producción de un área desfavorecida, sino que ésta contribuya a mantener el espacio habitado por su valor humano. Por lo tanto, los diferentes tipos de ayuda debieran ser entendidos, para que fuera claramente eficaz, en el marco de una política integral.

De otra parte, la política de ayudas sectorial tiene como unidad de delimitación geográfica el municipio o la explotación. En el concepto de política integral este marco es insuficiente, pues la problemática de las áreas de montaña necesitaría como mínimo ámbitos comarcales definidos por sus características humanas, económicas, funcionales, históricas, culturales y naturales. "En líneas generales, parece existir coincidencia en el objetivo básico a alcanzar, es decir, el mantenimiento del medio rural. Sin embargo, no existe una definición clara de las características de ese medio rural ni de las bases sobre las que que ha de asentar su desarrollo, ni tampoco de los instrumentos y medios a utilizar en la consecución de ese objetivo; por ello, puede ser de utilidad el establecimiento de tipologías de comarcas de acuerdo a sus características particulares con propósito de facilitar una orientación más precisa a las políticas a desarrollar, asi como valorar la adecuación de las acciones desarrolladas" (Murua, J.; Malagón, E.; Nebreda, A., 1996).

En lo referente a dotar de autonomía a las regiones o comarcas de montaña, algunas administraciones, tanto regionales como locales, son reticentes, pues ternen perder el control en la gestión del asunto objeto de ayudas o planificación. Estas reticencias se basan en dos puntos de vista diferentes:

Uno, el de las administraciones regionales que desconfían de la capacidad de los habitantes para gestionar su territorio y lleva a apartarlos de la marcha de sus asuntos (es la más corriente); esta política tiene ciertas connotaciones de un "despotismo ilustrado" de "todo para el pueblo pero sin el pueblo", y los planes elaborados corren el riesgo de nacer desarraigados y en muchos casos conllevan enfrentamientos sociales $y$, en el peor de los casos, de que nunca pasen de meros proyectos. 
Otro, el de las administraciones locales que, debido a la gran dispersión del hábitat de montaña, incurren a veces en una visión sesgadamente local de los problemas, cuando la magnitud de los mismos, hace necesario la presencia de organizaciones supralocales capaces de abordar con visión de conjunto las necesidades de una comarca o región, como pueden ser los relativos a infraestruturas. En ambos casos se debieran buscar zonas de consenso. La política regional debiera estar descentralizada en ámbitos homogéneos, susceptibles de atención socioeconómica de manera integral, para permitir a un gran número de actores conocer, reflexionar y trabajar en pro del desarrollo regional, que, en definitiva, no puede ser otra cosa que un desarrollo humano.

\section{BIBLIOGRAFÍA}

Colomo Ugarte, J. (1998): El Pirineo Navarro: Transformaciones y perspectivas en el uso humano del territorio. (Tesis doctoral). UNED, Facultad de Geografía e Historia, 910 págs.

FAYOS, E.; SANCHO, A. (1996): “Impactos globales de turismo en el desarrollo de las regiones: estado de la cuestión, Universidad de Valencia". Actas XXII Reunión de Estudios Regionales, Pamplona, 20-22 de noviembre de 1996.

Floristan, A. y Lizarraga, M.A (1990): “Cambios en los paisajes rurales del Pirineo Occidental español" en Homenaje al profesor A. BOUHIER, Paysages et Sociétés, Poitiers, 1990.

GINE, E. (1997): "La actividad turística como estrategia de desarrollo rural en zonas de montaña: el caso de la provinincia de Huesca" VIII coloquio de Geografia rural, Geographicalia, págs. 133-148.

GoRRIA IPAS, A.J. (1995): El Pirineo Central como espacio frontera. (Tesis doctoral). Universidad de Zaragoza, Facultad de Filosofía y Letras, 525 págs.

ISLA, M.M. (1993): "Patrimonio natural y turismo. (Entre la conservación y el desarrollo). Introducción». Cursos de Verano de la Universidad Internacional Menéndez Pelayo, Formigal-Huesca. 13-17 septiembre 1993, págs. 2-4.

Isus, A.G. (1989): “Tourisme et dévelopágsement régional des montagnes septentrionales d'Aragon et de Navarre (Pyrénées et Massifs Cantabriques) Un cas complexe d'intégration à l'économie moderne". L'Information Gégraphique, n. ${ }^{\circ} 4$, págs. 176-177.

LABORIE, J.P. (1989): “El marco institucional de las políticas de montaña en Francia». Estudios Territoriales (revista), $n .^{\circ} 29$, págs, 159-174.

LASANTA, T. y RuIz, P. (1990): «Especialización productiva y desarticulación espacial en la gestión reciente del territorio en la montaña de Europa Occidental» en Geocología de las áreas de montaña. Logroño, Geoforma Ediciones, págs. 267-295.

MAJORAL, R. (1997): "Desarrollo en áreas de montaña" VIII coloquio de Geografia rural, Geographicalia, págs. 23-49.

Marin Ordoqui, M.; Asin IRIgaray, J.M. (1994): "Las iniciativas comunitarias y su aplicación en Navarra". Boletín de Economía, n. ${ }^{\circ}$. Gobierno de Navarra, Departamento de Economía y Hacienda, págs. 43-64.

Murua, J.; Malagón, E.; Nebreda, A. (1996): "Zonas rurales de montaña en Navarra: situación y políticas de desarrollo, Dpto. Economia aplicada I, UPV-EHU," Actas XXII Reunión de Estudios Regionales, Pamplona 20-22 de noviembre de 1996

Rapun Gafate, M.; Iraizoz Apezteguia, B. (1993): «Pirineos: Las posibilidades de una economía de montaña. "La ganadería de montaña y la reforma de la PAC)". Cursos de Verano de la Universidad Internacional Menéndez Pelayo, Formigal-Huesca. 13-17 septiembre 1993, págs. $2-16$.

RuBio, M.T. (1989): “Emigración y cambio de actividad en El Pirineo". Espacio Tiempo y Forma, Serie VI, Geografia, t. 2, UNED, Madrid. págs. 155-168. 
SANCHEZ, J., y RoORiguez, V. (1989): "Politique socioestructurelle pour Zones d'Agriculture de Montagne (Deux années d'aide communautaire pour les ZAM espagnoles". Meditarrenée, págs. 23-32.

SÁNCHEZ, J. (1989): "Áreas de montaña: aproximación a su problematica actual». Revista. Espacio, Tiempo y Forma, Serie VI, Geografia, t. 2. UNED. Madrid. págs. 169-190.

SÁNCHEZ, J. (1997): «El "LEADER" de la Sierra de Segura (Castlla-La Mancha). Un programa innovador de desarrollo rural”. III Seminario Hispano-Húngaro sobre desequilibrios regionales. UNED-Instituto de Estudios Regionales de A.C.H., Pécs (Hungría), págs. 41-56.

SÁNCHEZ, J. (1997): "Pluriactividad y paisaje agrario en la montaña mediterránea" VIII coloquio de Geografía rural, Geographicalia, págs. 379-390.

STUCKI, E. (1989): Vigésimas Jornadas de EUROMONTANA 17-18-19 de mayo 1989. (Sustrai, Revista agropesquera, $\mathrm{n} .{ }^{\circ} 15$, Gobierno Vasco).

WYDER, J. Presidente de EUROMONTANA (1989): Vigésimas Jornadas de EUROMONTANA 17-18-19 de mayo 1989 (Sustrai, Revista agropesquera, $n{ }^{\circ}{ }^{15}$, Gobierno Vasco). 